\title{
Deformation Heterogeneities in Equal Channel Angular Pressing
}

\author{
Werner Skrotzki* \\ Institute of Solid State and Materials Physics, Dresden University of Technology, 01062 Dresden, Germany
}

Equal channel angular pressing (ECAP) is a severe plastic deformation (SPD) technique leading to refinement of the grain size of materials to submicron or even nano-size length scales. As a result SPD processed materials simultaneously possess high strength and moderate ductility and therefore have a high potential for technical applications. Because of this, much work has been devoted to the evolution of microstructure and texture and their relation to the mechanical properties. However, pressing materials through an angled channel is a complicated deformation process leading to deformation heterogeneities across the billet cross section manifested in gradients of microstructure and texture. Therefore, it is the aim of the present paper to give an overview focusing on the ECAP specific deformation heterogeneities and their related strength gradient in the billets produced. Based on the results reported, which are gained from experiment and simulation, some general conclusions on minimizing the deformation heterogeneities in ECAP are drawn. [doi:10.2320/matertrans.MF201926]

(Received February 20, 2019; Accepted April 15, 2019; Published June 25, 2019)

Keywords: severe plastic deformation, equal channel angular pressing, heterogeneity, microstructure, texture, strength

\section{Introduction}

Since the spurt in research activities pertaining to nanotechnology, much interest has arisen in processes involving severe plastic deformation (SPD). ${ }^{1-3)}$ Particularly, equal channel angular pressing (ECAP) $)^{4-8}$ has drawn considerable attention due to its potential to produce ultra-fine grained (UFG) or in some cases nanometer grain (NG) size materials in bulk form. It is well known by now that materials with such small grain sizes have extraordinary properties, ${ }^{9-11)}$ such as simultaneous high strength and moderate ductility as well as the capability of superplastic forming. Therefore, they have a high potential for technical applications.

In ECAP, a billet is deformed in a zone at the plane of intersection, so-called plastic deformation zone (PDZ), of two die channels of equal area cross-section (Fig. 1(a)). As the billet cross section remains nearly unchanged during ECAP, very high plastic strains, which cannot be readily obtained in more conventional manufacturing processes, such as rolling or extrusion, can be introduced in bulk materials by repeatedly pressing through the die. Depending on the cross section of the die, between the passes the billet may be rotated in different ways. ${ }^{12)}$ The routes used most frequently are sketched in Fig. 1(b). However, their effectiveness in refining the microstructure is debated (e.g. Ref. 13)). Because of a complex deformation mode operative in the ECAP process, there exists a gradient from the top to the bottom part of the ECAP deformed billet. Consequently, microstructure and texture formation is non-uniform across the billet. This has been demonstrated by the present author and coworkers ${ }^{14-30)}$ in some ECAP deformed face-centered cubic (FCC) and hexagonal close-packed (HCP) metals, and also by models based on visioplasticity, ${ }^{13,30-34)}$ finite element methods (FEM), both in 2-D and 3-D, ${ }^{13,30,35-55)}$ and by slip line theory ${ }^{56,57)}$ providing evidences of inhomogeneous deformation during ECAP. In general, plastic deformation takes place in the PDZ the shape of which sensitively depends on factors such as die geometry (die angle and corner roundness), processing conditions (contact friction,

*Corresponding author, E-mail: werner.skrotzki@tu-dresden.de back pressure (BP), temperature and pressing speed, ECAP route and number of passes) and plastic properties of the material itself. ${ }^{58)}$ It appears that the simple shear viewpoint is approached when the inner and outer corners of the die are sharp, there is no friction at the die walls and the material behaves rigid plastic. In the following this case is used as reference and referred to as ideal case. ${ }^{59,60)}$ In practice, however, these conditions may only be fulfilled partly. Therefore, to optimize the properties of ECAP deformed materials with regard to technological consequences, the inhomogeneity of deformation has to be studied in detail experimentally and compared with modeling of microstructure and texture. This is a very important aspect of the ECAP process, and has rarely been addressed.

Thus, it is the aim of the present paper to give an overview focusing on the deformation heterogeneities in ECAP on macro-scale and their consequences on the mechanical properties of the billets produced. The paper concentrates on the steady region of the billets and excludes the front and rear parts, where the deformation process is most heterogeneous. These parts generally extend with increasing number of passes by this shortening the steady region. In the following chapters the factors leading to heterogeneous flow across the billet cross section will be dealt with in detail. Excluded are shear bands sometimes observed which arise from flow instabilities and lead to deformation heterogeneity along the billet. Heterogeneous flow leads to heterogeneities manifested in gradients of microstructure, texture and mechanical properties. Based on the results reported, which are mainly gained from experiment but also from simulation, some general conclusions on minimizing the deformation heterogeneities in ECAP are drawn.

\section{Design of ECAP Tool}

There are many possibilities to change the design of the ECAP tool. To allow for different process routes, the die cross section must be axisymmetric. Therefore, cross sections used so far generally have round or square shape. Although enabling only $90^{\circ}$ rotations of the billet, the latter is preferred, because it leads to more accurate rotations. Important design 


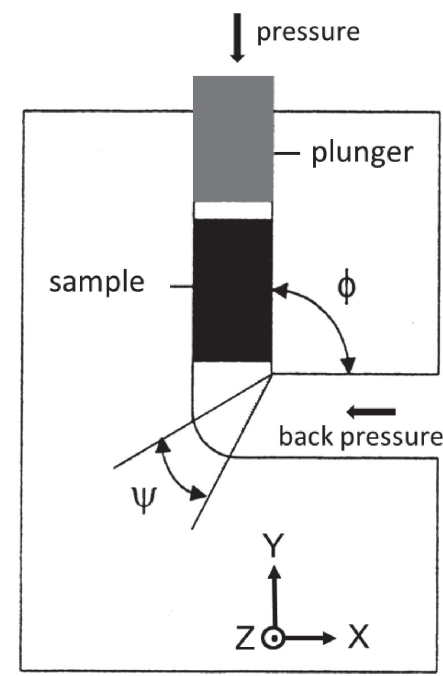

(a)

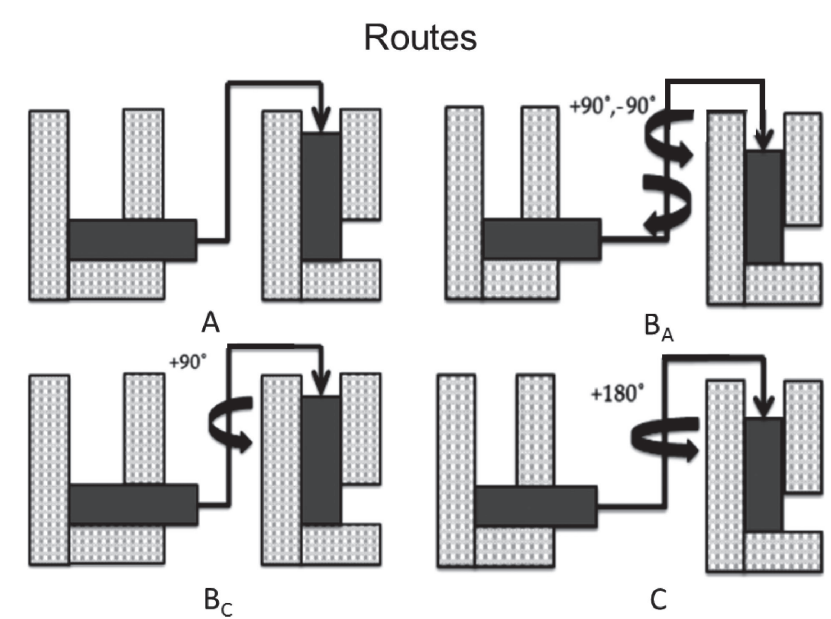

(b)

Fig. 1 (a) Sketch of the ECAP die with die angle $\Phi$ and outer corner angle of channel $\Psi$ indicated. ${ }^{64)}$ (b) ECAP routes mainly used. ${ }^{99}$ )

parameters are die angle and roundness of the channel corners. Moreover, sophisticated ECAP tools are constructed with movable walls to reduce friction. Reduction of friction generally helps to decrease the maximum load required for ECAP, which scales with the billet cross section and length, but also depends on the strength and work-hardening of the material. ${ }^{61-63)}$ In anyway, upscaling is limited by the tool materials used. In practice, slightly smaller cross sections are used for the outlet channel to avoid the need for lightly grinding the billets between repetitive pressings because of their elastic rebound after extrusion.

\subsection{Die angle and roundness of channel corner}

The effect of die angle $\Phi$ and outer corner angle $\psi$ (Fig. 1(a)) on the shear strain $\gamma$ produced during ECAP in the ideal case for $N$ passes is given by the following equation ${ }^{64)}$

$$
\gamma=N\left[2 \cot \left(\frac{\phi}{2}+\frac{\psi}{2}\right)+\psi \operatorname{cosec}\left(\frac{\phi}{2}+\frac{\psi}{2}\right)\right]
$$

Figure 2(a) shows the equivalent strain $\varepsilon=\gamma / \sqrt{3}$ as a function of die and outer corner angle for one pass. It is seen, that $\varepsilon$ decreases with increasing die angle and increasing outer corner angle the effect being more pronounced for small die angles. In contrast, FEM calculations (Fig. 2(b)) show that the strain is heterogeneous from top to bottom of the ECAP sample. ${ }^{38)}$ In the case of sharp die corners the strain slightly increases from top to bottom except in a small section at the top and the bottom where the billet experiences less strain. With increasing roundness of the outer die corner these regions extend, the extension being larger at the bottom. The average equivalent strain in the relatively homogeneous middle section follows the analytical solution given by eq. (1). A die with $90^{\circ}$ die angle and sharp corners best approaches the ideal case, therefore this die design has been used most.

\subsection{Movable walls}

Reducing friction at the channel walls reduces the processing load and helps to deform stronger materials and
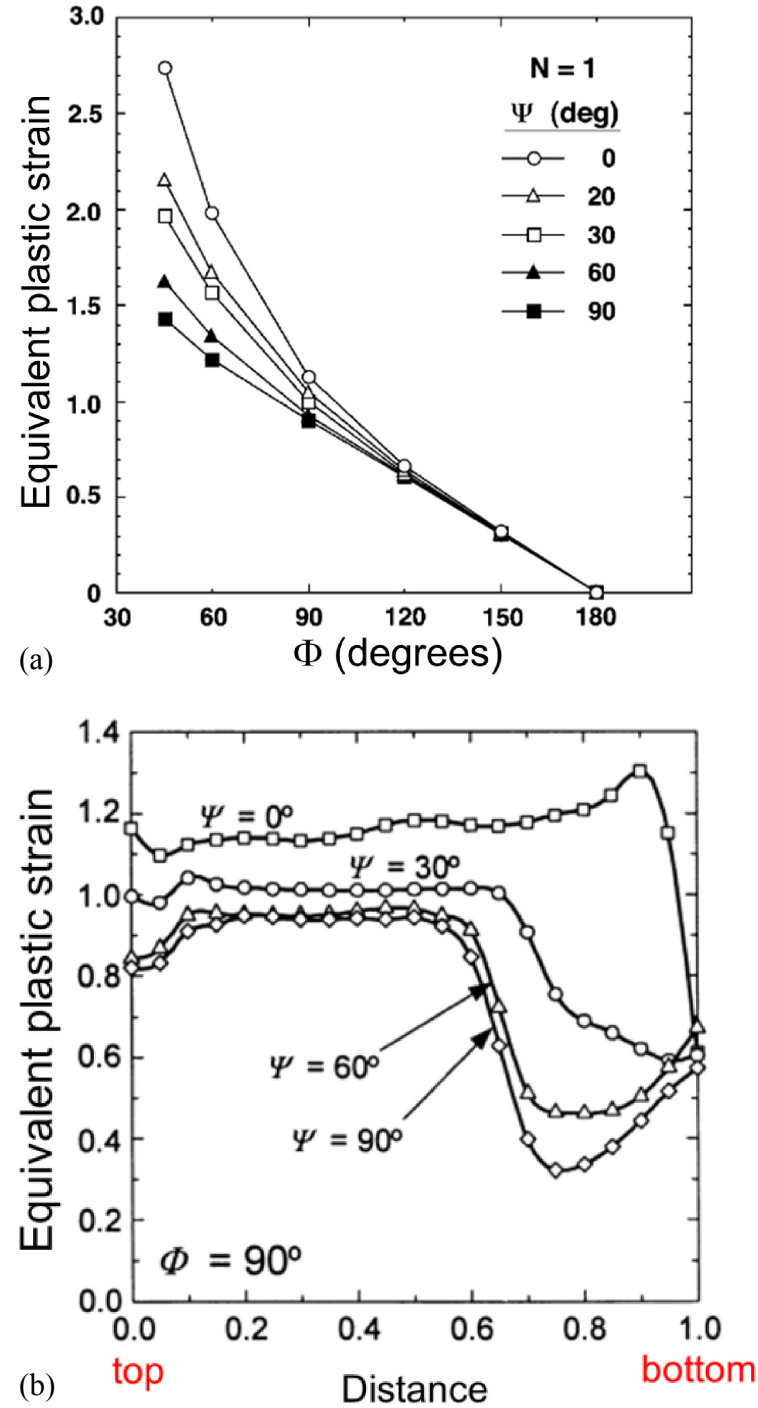

Fig. 2 (a) Variation of equivalent plastic strain with die angle for different outer corner angles (eq. (1)). ${ }^{98)}$ (b) Effect of curvature angle on equivalent plastic strain as a function of distance from top of the billet predicted by numerical analysis. ${ }^{38)}$ 

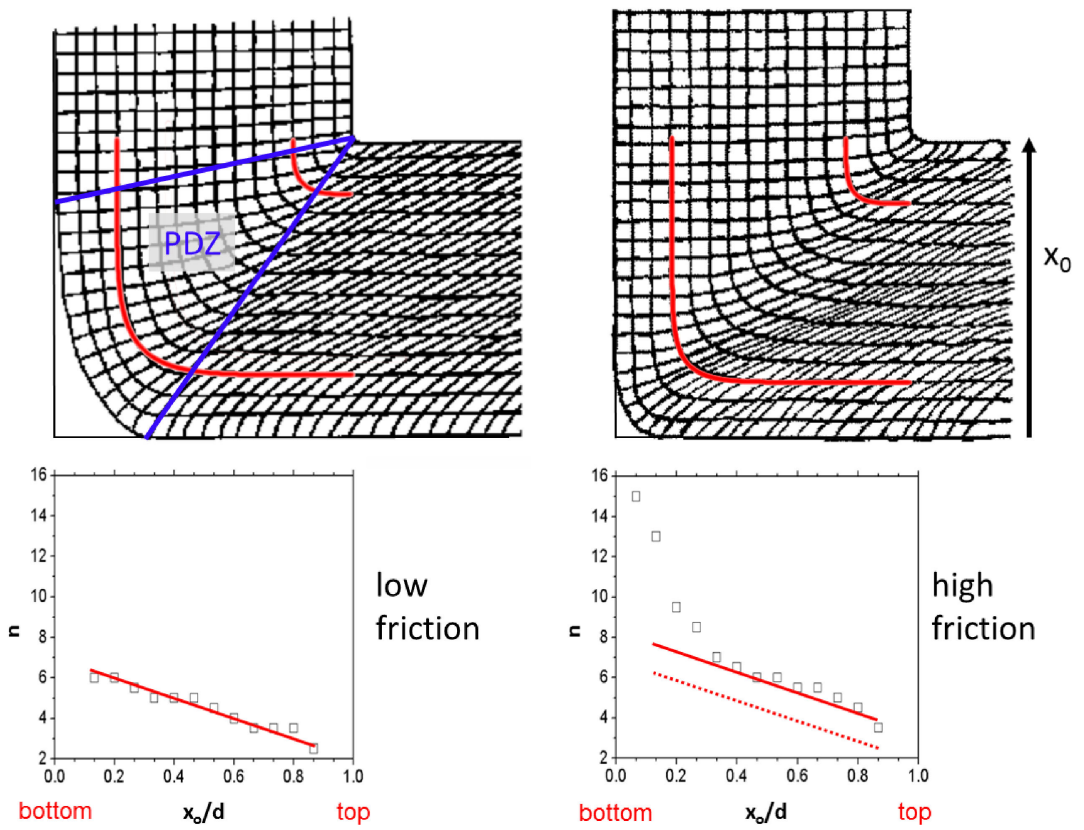

Fig. 3 Marker grids showing the deformation taking place during ECAP for low and high friction with the plastic deformation zone (PDZ) indicated. ${ }^{31)}$ Flow line parameter $n$ from top to bottom of the billets fitted according to the flow line model of Tóth $e t$ al. ${ }^{69,70)}$

upscale the tool to larger billet dimensions. This can be achieved with channel walls moving with the sample. For dies with rectangular channel cross section the walls which are suitable are two side walls of the inlet channel and the bottom wall of the outlet channel. ${ }^{63)}$ If the bottom wall is not sliding, then three movable side walls of the inlet channel are possible. ${ }^{65)}$ While on the one hand a friction-reduced die needs lower processing loads, on the other hand it leads to a larger PDZ. However, if the sliding bottom wall is constructed such that it consists of a lip closing the outer channel, then this bottom wall can be used to apply a back pressure in an elegant way. Back pressure reduces the PDZ, respectively outer corner gap (s. 3.3), leading to more homogeneous deformation under much defined conditions.

\section{Processing Conditions}

The processing conditions which can be changed for ECAP are temperature, pressing speed, friction, back pressure, route and number of passes. As these parameters are more or less interrelated, it is difficult to discuss its sole effect on the development of microstructure, texture and mechanical properties. Usually, ECAP is performed at room temperature to keep thermally activated processes (dynamic recovery and dynamic recrystallization) weak. Moreover, low pressing speeds are used (in the order of $1 \mathrm{~mm} / \mathrm{s}$ ) to minimize a temperature rise in the PDZ due to adiabatic heating. ${ }^{62)}$ Therefore, in the following the effect of friction, back pressure, route and number of passes on deformation heterogeneities will be demonstrated. The most ambiguous parameter is friction, because it is for example influenced by back pressure inducing a hydrostatic pressure or by the number of passes increasing the pressing load due to strengthening of the material.

\subsection{Contact friction}

In the ideal case deformation is confined to the shear plane. However, if frictional forces are present during processing, they spread the deformation zone from the shear plane over the fan-shaped PVZ. In the case of equal friction in the channels, the PVZ is symmetrical about the ideal shear plane, but in general friction is higher in the outlet channel (especially at the bottom wall) leading to a larger spread of the PDZ into the inlet channel (Fig. 3). If the material has the capability to work-harden, then the material does not tend to fill the outer die corner and a free surface is formed. Similar to the PDZ, the corner gap is asymmetrical with respect to the shear plane if the frictional forces are different. Increasing the friction reduces the corner gap and changes the flow behavior to less rounded flow lines. This is demonstrated by an increasing $n$ parameter which governs the curvature of the flow lines (s. below). If friction is too high, it leads at the outer corner to a so-called dead metal zone (DMZ) which does not take part in the deformation process. This is nicely demonstrated by an ECAP experiment using layered colored plasticine (Fig. 4).

\subsection{ECAP route and number of passes}

It is the purpose of multi-pass ECAP processing to accumulate strains and by this modify the microstructure (dislocation density, twin density, grain size, fraction of high angle boundaries) of the material. It is a general observation that after a certain strain a steady state microstructure develops. The steady state grain size (nearly equiaxed, aspect ratio $\leq 2$ ), which for all routes is comparable seems to be reached fastest with route $B_{C}{ }^{66}$ ) This may intuitively be explained by the different shear planes and distortions induced by the routes on a material element. ${ }^{67)}$ The drastic change in microstructure is in the first pass. Because of a strain on the order of one the material is in or beyond stage IV of work-hardening. Thus, further straining quite fast 

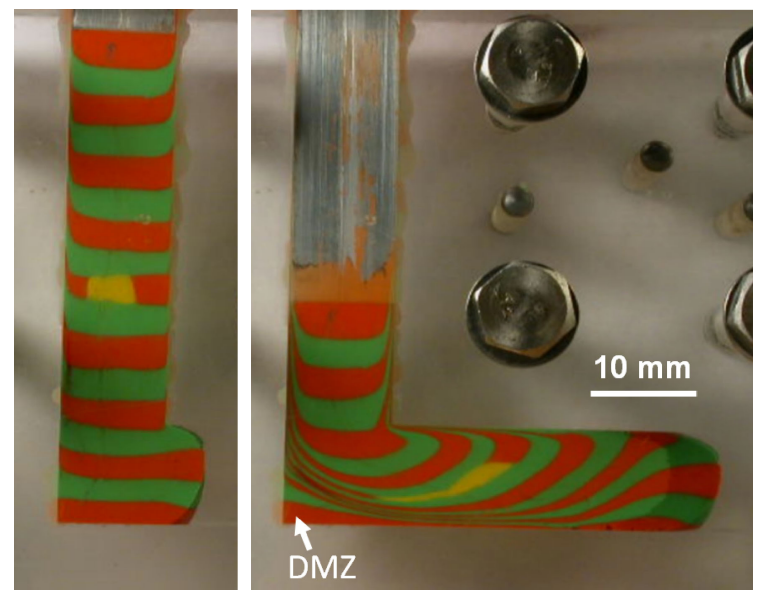

Fig. 4 ECAP of colored plasticine showing the inhomogeneous straining with dead metal zone (DMZ) indicated.

leads to saturation. As a consequence, the microstructure with increasing number of passes is homogenized across the billet, as is generally observed, e.g. Ref. 63). This process certainly depends on the material properties, such as initial microstructure, work-hardening and twinning behavior, which may be interrelated.

Besides the change of microstructure during ECAP, also the texture changes. However, its change with route and passes is totally different. While for the microstructure a steady state is reached, this does not hold for the texture. The strain of one ECAP path is generally not high enough to completely overprint the texture existing at the beginning of each pass. The textures are also different because of the strain path changes taking place in each route due to rotation of the billet, which also rotates the texture in the same way. Thus, texture gradients with respect to intensity and position of texture components change with each pass depending on the route. In routes $A$ and $C$ a random starting texture will change to monoclinic sample symmetry, which is the symmetry of simple shear, the main deformation mode of ECAP. In routes $B_{A}$ and $B_{C}$ after the first pass, because of $90^{\circ}$ rotation of the billet about the longitudinal axis, the sample symmetry changes to triclinic and during further passes is never fully changed to monoclinic. Thus, the texture does not only change from top to bottom (along $Y$ ) but also in transverse direction (along $Z$ ) complicating the situation. This will be demonstrated in the following.

The textures shown are mainly represented using the orientation distribution function (ODF) method, which provides a better resolution of texture components than pole figures. (The sample coordinate system to calculate the ODFs from pole figures is chosen with $X, Y, Z$ parallel to the extrusion direction, normal and transverse direction, respectively, s. Fig. 1(a). The Euler angles are used in Bunge notation. ${ }^{68)}$ For monoclinic and triclinic sample symmetry the ODF representations are extended to $\varphi_{1}=180^{\circ}$ and $\varphi_{1}=$ $360^{\circ}$, respectively.) This is particularly relevant keeping the goals of the texture investigation in mind, as one needs to address and account for small shifts in location of texture components, while describing the heterogeneities. Texture simulations are carried out with Tóth's flow line model of ECAP, ${ }^{69,70)}$ an analytical approach, where non-uniform

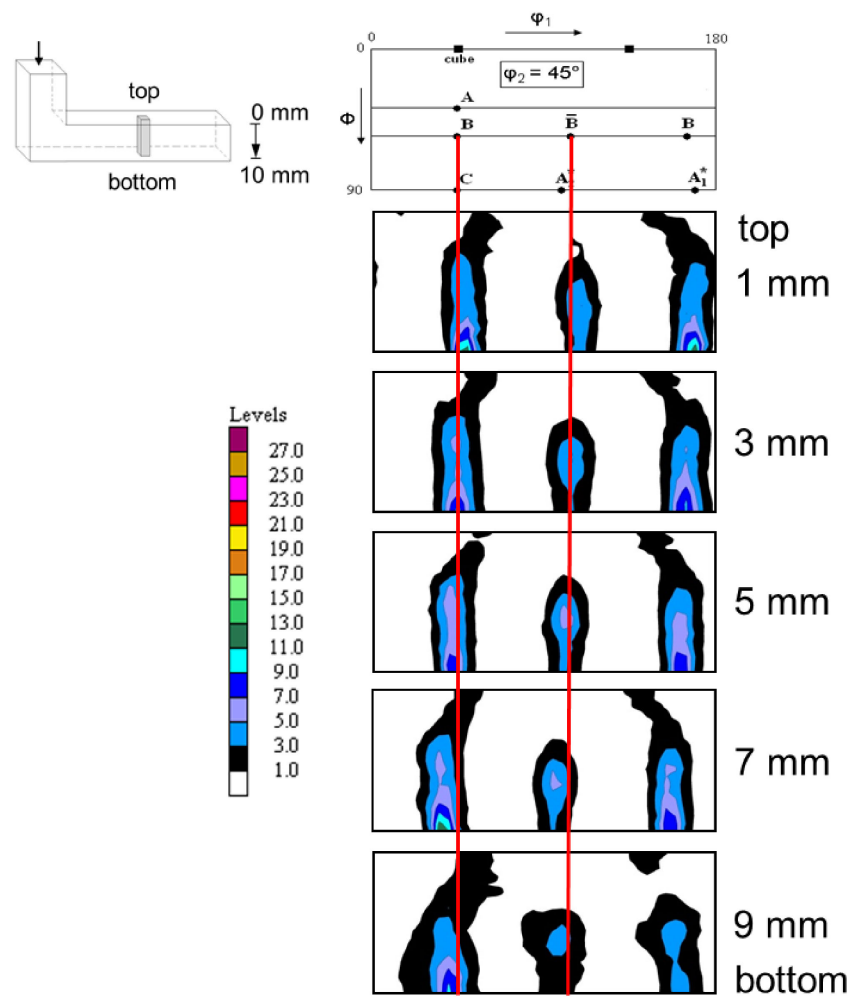

Fig. 5 Measured ECAP texture of copper after one pass in $\varphi_{2}=45^{\circ} \mathrm{ODF}$ section subject to the distance from the top of the billet. Intensity levels are given in multiples of a random distribution. Upper key figure shows the ideal orientations in ECAP. ${ }^{66)}$

deformation can be easily incorporated by changing the shape of the flow lines. This attribute of the model makes it one of the most suitable models for studying texture heterogeneities.

The local textures presented for ECAPed copper $(4 \mathrm{~N}+$, room temperature, lubricated rectangular die $(10 \mathrm{~mm} \times$ $10 \mathrm{~mm}$ ) with sharp corners) are measured by synchrotron radiation on small pins taken at the middle (in $X$ ) of the billet and at three positions along $Z(L=$ left, $M=$ middle and $R=$ right) for monoclinic and triclinic sample symmetry, respectively, with the pin axis parallel to the $Y$ axis. The texture is measured in a small volume at five positions along the $Y$ axis. ${ }^{66)}$ The texture after one pass is presented in the $\varphi_{2}=45^{\circ}$ ODF section in Fig. 5. This section is sufficient to show the main texture components developing during simple shear in FCC metals (Table 1). The positions of the ideal shear components plus cube component in the ODF section are shown in the key figure. It is evident that the main shear components exist after one pass, but they exhibit different intensities. Moreover, the intensities of the components as well as their deviations from the ideal positions change from top to bottom of the billet. A quantitative description of the intensities and the deviations in $\varphi_{1}$ for one pass is given in Figs. 6(a) and (b), respectively. A similar texture analysis after two passes of route $B_{C}$ in the left, middle and right pins is given in Fig. 7.

After one pass, $C$ and $A_{1}{ }^{*}$ are the main texture components followed by $B / \bar{B}$ (Fig. 6(a)). The texture intensity is quite homogeneous except in the lower quarter of the billet where it slightly decreases, for more details see Ref. 23). In 
Table 1 Ideal texture components in simple shear of FCC metals.

\begin{tabular}{|c|c|}
\hline $\begin{array}{c}\text { Component } \\
\text { designation }\end{array}$ & $\begin{array}{c}\text { Miller indices } \\
\text { (shear plane) [shear direction] }\end{array}$ \\
\hline $\mathrm{A}$ & $(11 \overline{1})[1 \overline{1} 0]$ \\
\hline$\overline{\mathrm{A}}$ & $(\overline{1} \overline{1} 1)[\overline{1} 10]$ \\
\hline $\mathrm{B}$ & $(11 \overline{2})[1 \overline{1} 0]$ \\
\hline$\overline{\mathrm{B}}$ & $(\overline{1} \overline{1} 2)[\overline{1} 10]$ \\
\hline $\mathrm{C}$ & $(100)[0 \overline{1} 1]$ \\
\hline $\mathrm{A}_{1}{ }^{*}$ & $(11 \overline{1})[2 \overline{1} 1]$ \\
\hline $\mathrm{A}_{2}{ }^{*}$ & $(1 \overline{1} 1)[\overline{2} \overline{1} 1]$ \\
\hline $\begin{array}{c}\{111\} \text { fibre } \\
\text { or } A \text { fibre }\end{array}$ & $\{111\}<\mathrm{uvw}>$ \\
\hline $\begin{array}{c}<10>\text { fibre } \\
\text { or } B \text { fibre }\end{array}$ & $\{\mathrm{hk}\}<110>$ \\
\hline
\end{tabular}

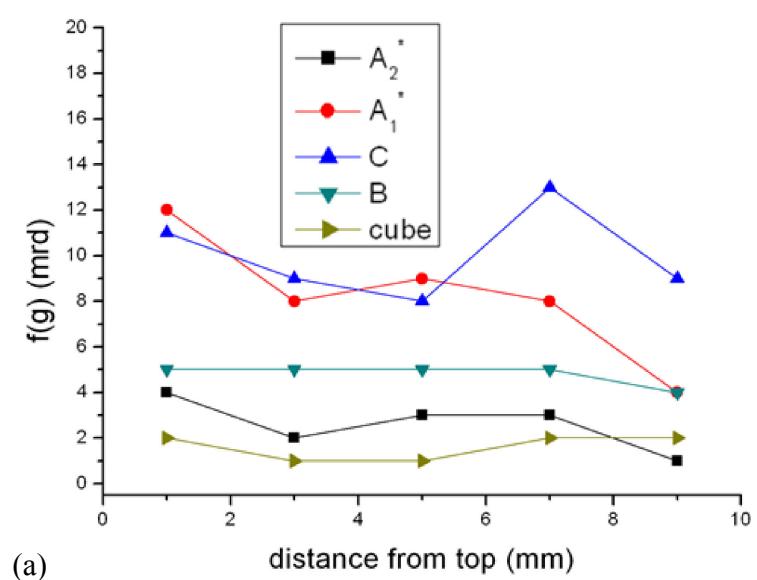

(a)

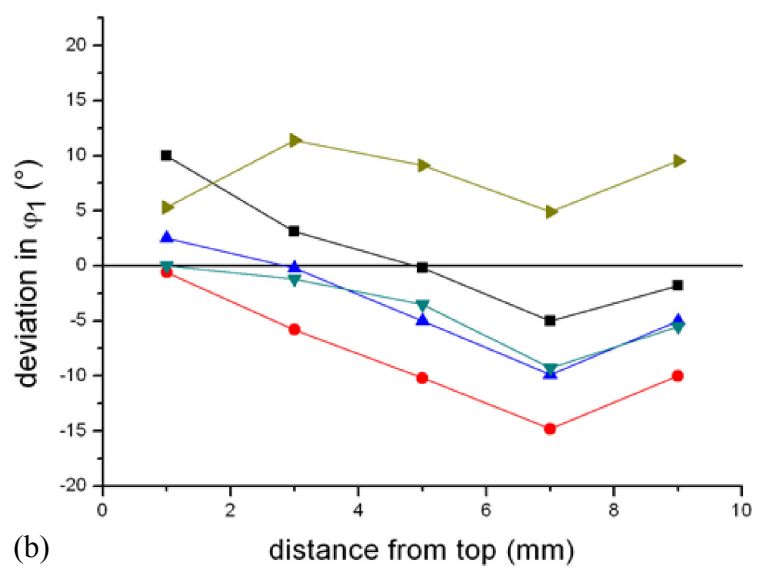

Fig. 6 (a) Intensity of the texture components of copper after one ECAP pass subject to position in the billet from the top to bottom. (b) Deviation in $\varphi_{1}$ of texture components from ideal positions, negative values indicate a shift towards decreasing values of $\varphi_{1}{ }^{66)}$

contrast, after two passes of route $B_{C}, B / \bar{B}$ is dominating with a pronounced intensity (Fig. 7). In addition to the gradient in $Y$, there is a gradient from left to right (along $Z$ ) changing from top to bottom of the billet. While in the middle pin $B$ and $\bar{B}$ almost have the same intensity and show the same trend from top to bottom, on the left and right side the same trend only holds for $B$ and $\bar{B}$, respectively. The corresponding other component after a maximum at $3 \mathrm{~mm}$ from the top significantly decreases. In all cases, there is a lower intensity in the upper quarter of the billet.

With respect to the deviation in $\varphi_{1}$ from the ideal texture components in pass 1 , there is a continuous decrease of all components from positive to negative values (Fig. 6(b)). The upper gradient of route $A$ depends on the material and number of passes. ${ }^{20}$ ) The situation is different and more complex in the lower quarter of the billet. ${ }^{23}$ In the case of pass 2 of route $B_{C}$ the deviations are quite constant between 3 and $7 \mathrm{~mm}$ from the top, while in the rest they generally deviate, mostly to lower positive, respectively negative values (Fig. 7). In all cases, the deviation sequence of the components is the same with $A_{1}{ }^{*}$ always displaced to negative angles. Similar observations are made after 3 and 4 passes. $^{66)}$

Also included in Figs. 6 and 7 is the oblique cube component. While in general their intensity is quite low, its deviation in $\varphi_{1}$ from the ideal position is maximum in positive direction. The oblique cube component has also been observed in nickel deformed route $A$ at $400{ }^{\circ} \mathrm{C} .{ }^{18)}$ It has been shown that for all passes its intensity increases from top to bottom of the billets. Separating the texture of the recrystallized (large) grains from that of the deformed matrix (smaller grains) clearly proved that the oblique cube component is related to dynamic recrystallization. This component has also been observed for dynamically recrystallized high purity aluminium, ${ }^{22)}$ s. 4.2 .

\subsection{Back pressure}

Back pressure enhances the workability of the material and therefore is especially useful for less ductile materials. ${ }^{6)}$ Porosity usually developing during ECAP is suppressed by BP leading to ductile fracture of the material during tensile testing. ${ }^{71,72)}$ As shown by an analysis of FEM, BP changes the flow behavior in the die. ${ }^{54)}$ For strain hardening metals, like technically pure aluminum AA 1100, with increasing BP the outer asymmetric corner gap is closed and above a certain level of BP (about $100 \mathrm{MPa}$ ) a DMZ is produced. Accordingly, the PDZ of the die channels first decreases and then increases again. With decreasing PDZ the overall strain rate along the intersection plane increases and the strain rate distribution becomes more uniform and symmetric. The equivalent plastic strain in the billet is almost constant at 1.0 in a range of 0.1 to 0.7 of the relative distance from the top surface. In the upper section it is slightly smaller, while in the lower section it is much lower and increases with increasing BP. In contrast, in quasi-perfect plastic materials, like the peak-aged aluminum alloy AA 6061-T6, already without BP no corner gap is formed and with increasing BP the PDZ increases, while the strain rate distribution does not change too much. The equivalent plastic strain is constant at 1.0 within a range of 0.1 to 0.8 of the relative distance from the top surface. In the upper section it is slightly smaller, while in the lower section it drastically increases for all BPs applied. The broadening of the PDZ with BP has been shown by scribed grids on furnace-cooled aluminum alloy AA 6016$0 .{ }^{73)}$ With increasing BP there is a decrease in average cell size, increase in cell wall thickness and increase of dislocation density within the cells and cell walls. Moreover, 

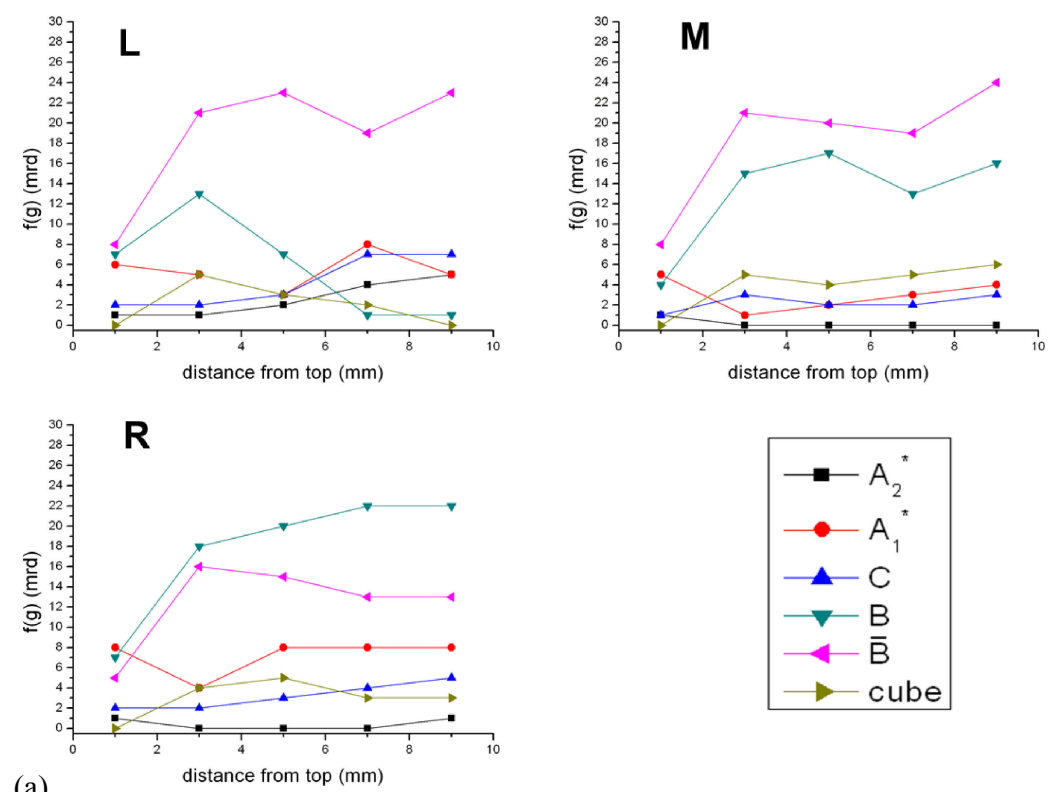

(a)
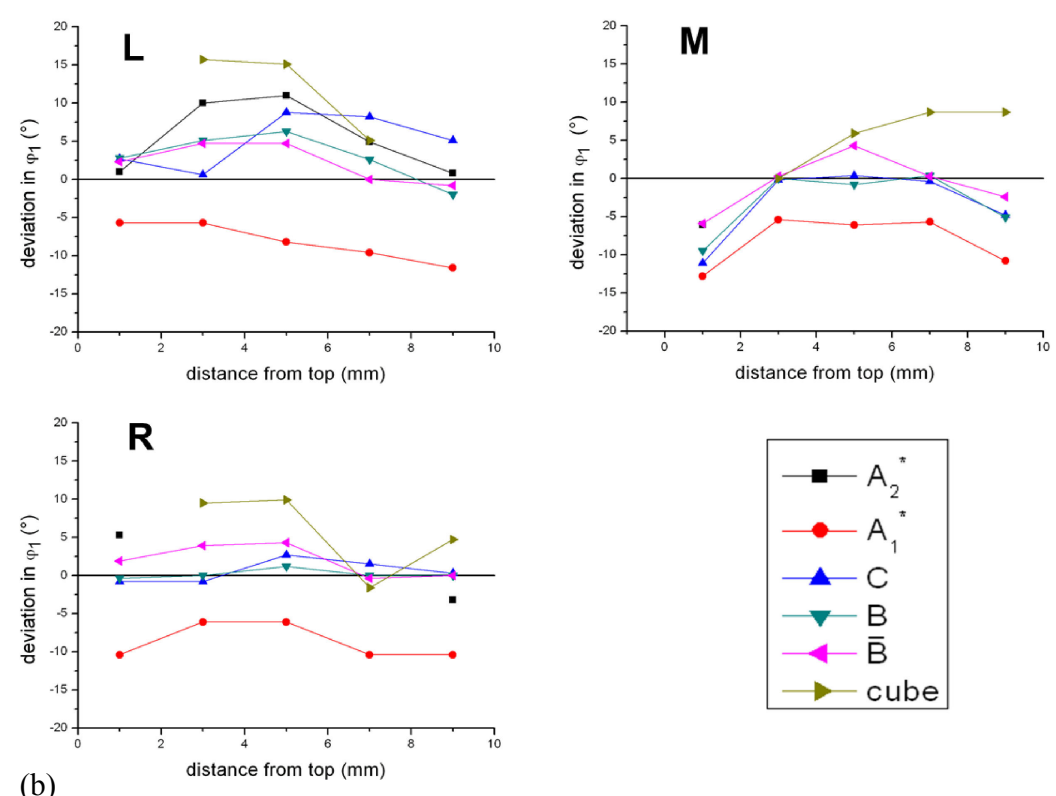

(b)

Fig. 7 (a) Intensity of the texture components of copper after two ECAP passes route $B_{C}$ subject to position in the billet from the top to bottom (left $L$, middle $M$ and right $R$ pin). (b) Deviation in $\varphi_{1}$ of texture components from ideal positions, negative values indicate a shift towards decreasing values of $\varphi_{1}{ }^{66}$ )

the formation of HAGBs is faster with strain. This has been shown for AA $6016-\mathrm{O}^{74,75)}$ by applying a BP of $200 \mathrm{MPa}$. If the material is deformed at temperatures, where dynamic recrystallization takes place (AA $5024,300^{\circ} \mathrm{C}, 100 \mathrm{MPa} \mathrm{BP}$ ), it has been found that recrystallization is enhanced by $\mathrm{BP}^{76}$ ) As the shear deformation during ECAP is quite large, there is pronounced texture formation. ${ }^{58)}$ Due to non-uniform strain rate distribution in the PDZ and hence heterogeneous strain distribution in the billet texture development is not homogeneous throughout the billet. There exists a gradient from top to bottom in the deformed billet ${ }^{14-30)}$ and consequently this affects the overall mechanical properties. The effect of BP on the overall texture formation has been shown for AA 6016-O. ${ }^{77)}$ Application of a BP of $200 \mathrm{MPa}$ results in a positive rotation of the typical shear texture components about the transverse direction. This translation reduces in magnitude with increasing number of ECAP passes until no translation exists after eight and more passes.

To better understand the effect of BP on the flow behavior and texture development one ECAP pass has been performed on technically pure aluminum alloy AA 1050 under different BPs. ${ }^{30)}$ For this a sophisticated large-scale ECAP tool $(50 \mathrm{~mm} \times 50 \mathrm{~mm})$ especially designed for low friction was used with moving outer walls and sliding bottom. ${ }^{63)}$ The flow pattern was made visible by a grid scribed on the transverse section of a billet split in the middle. Texture measurements were done by X-ray diffraction on the normal plane as a function of distance from the top of the billet. Special care was also taken to characterize the initial microstructure and texture. Based on the flow line pattern the texture was simulated with Toth's flow line model ${ }^{69,70)}$ and compared with experiment. 


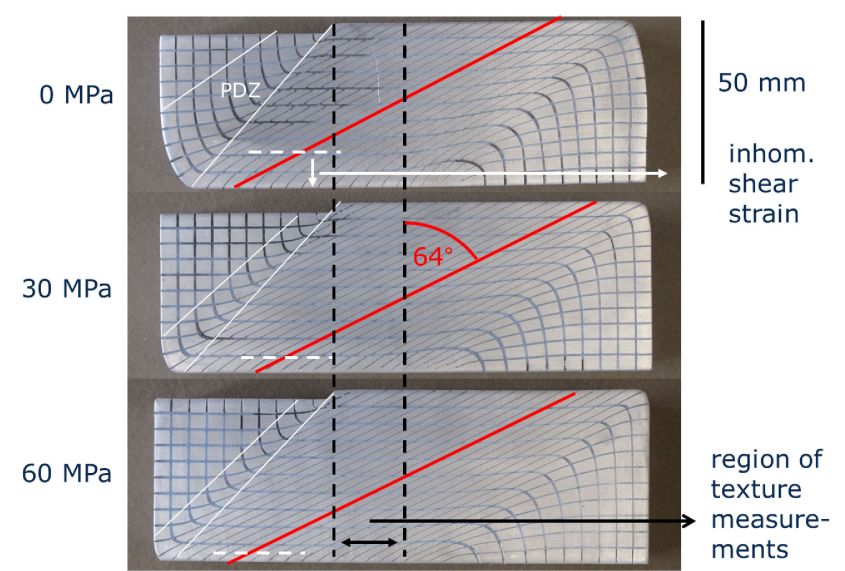

Fig. 8 Change of flow line pattern with back pressure for $2 \mathrm{~N}+$ aluminium The plastic deformation zone (PDZ), zone of inhomogeneous shear strain and region of texture measurement are marked. The shear angle is about $\left.64^{\circ} \cdot 30\right)$

The change in flow characteristics with BP is demonstrated in Fig. 8. It is clearly seen, that during ECAP without BP an asymmetric corner gap is formed which limits the PDZ marked by the white pointed lines. Quantitative evaluation of the flow pattern was made possible from the deformed grid scribed on split extra samples of shorter length. In the tail section of the billet the area of the corner gap decreases with increasing BP. Similarly, the area of the asymmetric fan-like PDZ decreases. The only border point staying fixed is the upper channel corner which is intersected by the lower border line. In the steady region the grid is homogeneously sheared yielding an angle of about $\alpha=64^{\circ}$ with ED, which is in agreement with the theoretical shear angle given by $\alpha=$ $\arctan 2=63.4^{\circ}$. The inhomogeneous deformed bottom part decreases with increasing BP from $10 \mathrm{~mm}$ at zero BP over $5 \mathrm{~mm}$ at $30 \mathrm{MPa}$ to $2.5 \mathrm{~mm}$ at $60 \mathrm{MPa} \mathrm{BP}$. It is also shown that with increasing BP the head region approaches an ideally undeformed triangle. These results agree well with those found by FEM analysis.

The initial microstructure is a typical rolling microstructure consisting of grains flattened in the rolling plane (grain size $\approx 20 \mu \mathrm{m}$, aspect ratio $\approx 2.5$, while the texture is a typical rolling texture of FCC metals with a strong copper and brass component, a minor Goss and very weak cube component.

ECAP leads to grain refinement which becomes more pronounced with increasing BP, compare Ref. 75). The size and aspect ratio of the newly formed grains is about $3 \mu \mathrm{m}$ and 2.5 , respectively. There exists a preferred extension of the (initial) grain structure at an angle of $26^{\circ}=90^{\circ}-\alpha$ with regard to the shear direction. Moreover, shear features exist along the trace of the channel intersection plane. The texture is a typical shear texture changing from top to bottom with regard to intensity and deviation from the ideal position of the components. These two parameters are quantitatively displayed for all samples in Fig. 9. According to these figures three zones may be distinguished from top to bottom of the billet: Upper zone I of $10 \mathrm{~mm}$ with strong intensity variations and strong deviations of the components from their ideal positions, a rather homogeneous zone II from 10 to $30 \mathrm{~mm}$ with respect to intensity and very small deviation $\left( \pm 5^{\circ}\right)$ from ideal position and a zone III above $30 \mathrm{~mm}$, in which the $A_{1}{ }^{*}$ component is split. Here, in general, the intensities of the components decrease and stronger deviations exist from the ideal positions. The zone of inhomogeneous shear strain defined in Fig. 8 can only be correlated with texture for the sample deformed without BP. In this zone there is a general decrease in intensity and an increase in deviation.

Zones I and III may be related to the zones found by FEM analysis, in which the equivalent plastic strain rate along the channel intersection plane is significantly higher than in zone II. ${ }^{54)}$ In the rather homogeneous zone II with increasing $\mathrm{BP}$ there is a relative increase of the intensity of the components except that of $C$ which goes over a maximum. As a result the maximum component at 0,30 and $60 \mathrm{MPa} \mathrm{BP}$ is $A_{1}{ }^{*}, C$ and $\bar{A}$, respectively. The texture results differ from those reported by Ref. 77). The reason may be the smaller die, higher BP and different $\mathrm{Al}$ alloy.

To quantify the flow behavior during ECAP the symmetric flow line function defined in the flow line model of Tóth ${ }^{69,70)}$ has been fitted to the deformed grids. The flow line exponent increases almost linearly from top to bottom with the slope being larger in the bottom part above $30 \mathrm{~mm}$. There is practically no change from 30 to $60 \mathrm{MPa} \mathrm{BP}$. Taking the flow line exponents derived from experiment the ECAP textures for the BPs of 30 and $60 \mathrm{MPa}$ have been simulated. There is quite good agreement between experiment and simulation when using octahedral and non-octahedral slip with equal critical resolved shear stresses. Even some characteristic features of the ODF can be reproduced. As the flow lines do not change from 30 to $60 \mathrm{MPa} \mathrm{BP}$ the change of the experimental texture with BP cannot be explained by Tóth's flow line model alone. Moreover, the splitting of the $A_{1}{ }^{*}$ component cannot be reproduced.

It is generally accepted that BP enhances friction of the billet at the channel walls, this effect being strongest at the bottom wall. The interrelated effect of friction and BP on flow in ECAP has been shown by Bowen. ${ }^{31)}$ Therefore, both influences are hard to separate. By using a friction-reduced tool, as done here, BP on the one hand leads to narrowing of the PDZ by this approaching the simple shear mode. On the other hand the microstructure is more refined. This seems to be a clear hydrostatic pressure effect. Hydrostatic pressure reduces the diffusivity of the material and hence dynamic recovery. As a result the microstructure is more refined. Evidently, this effect leads to a texture change.

The microhardness (Brinell hardness HBW 2.5/62.5) has been measured from top to bottom of the samples (Fig. 10). In the initial state the microhardness is constant over the thickness. After one ECAP pass it almost doubles and linearly increases from top to bottom by $7 \%$, except in the zone of inhomogeneous shear at the bottom where it decreases again. The width of this zone decreases with back pressure. The slight hardness gradient $(0.06 \mathrm{HBW} / \mathrm{mm})$ does not depend on the back pressure. Similar observations have been made by Frint et al. ${ }^{79,80)}$ on the aluminium alloy 6060 in the solution-treated state. The hardness increase of this alloy without BP is $7 \%$ as well. However, because of its higher strength the hardness gradient is $0.1 \mathrm{HBW} / \mathrm{mm}$. Tensile tests in $X$ direction yield an increase in ultimate tensile strength 

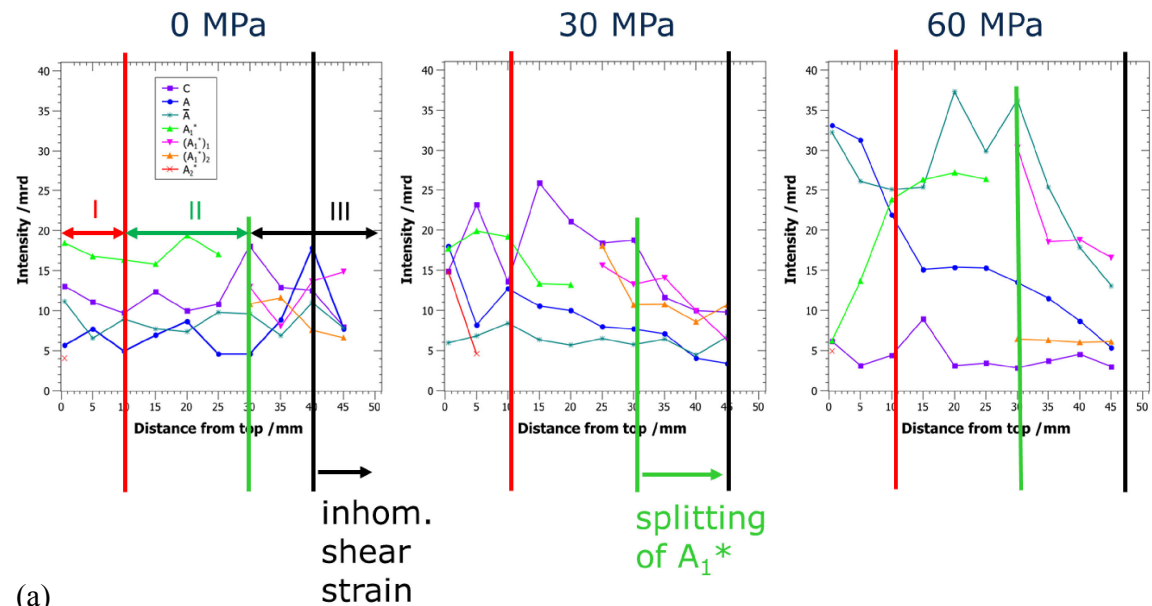

(a)

strain
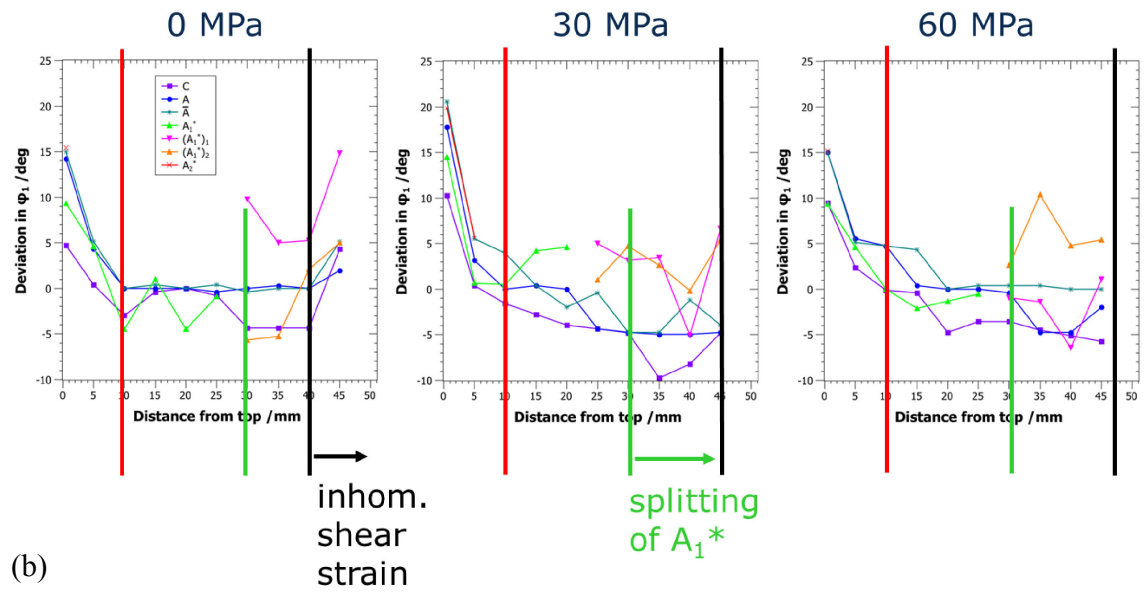

Fig. 9 (a) Intensity of texture components from top to bottom of the billet $(2 \mathrm{~N}+$ aluminium after one pass at different back pressures): Zones of inhomogeneous shear strain, strong variation of intensity of texture components and splitting of $A_{1}{ }^{*}$ component are marked by black, red and green lines, respectively. Three different zones are marked I, II and III. (b) Corresponding deviation of texture components from ideal shear position. ${ }^{30}$
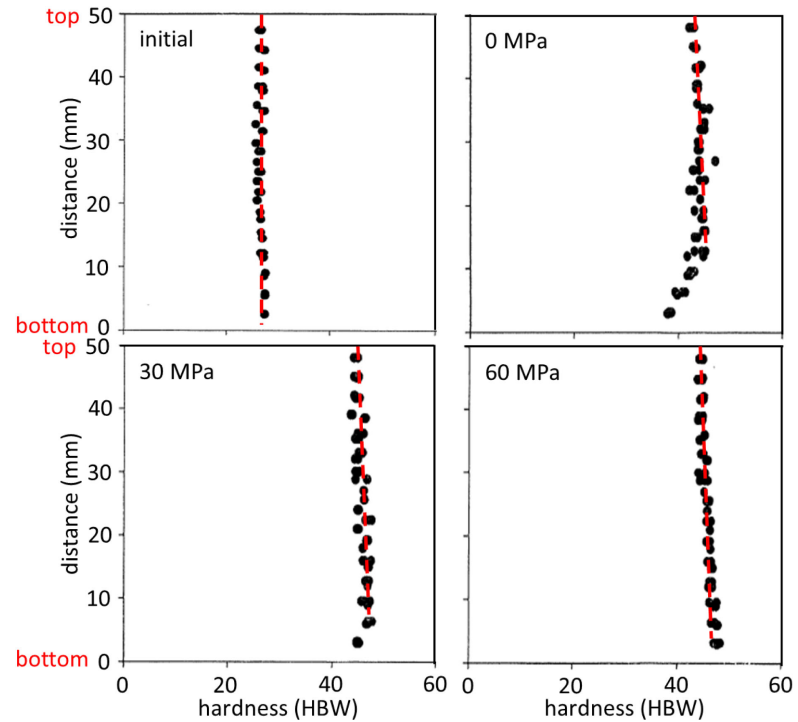

Fig. 10 Brinell hardness measured from top to the bottom of the billets as a function of back pressure for technical pure aluminium after one ECAP pass.

of $11 \%$ and $6 \%$, corresponding to hardness gradients of $5.8 \mathrm{MPa} / \mathrm{mm}$ and $3.4 \mathrm{MPa} / \mathrm{mm}$, for $\mathrm{BPs}$ of $0 \mathrm{MPa}$ and $200 \mathrm{MPa}$, respectively. ${ }^{81)}$
Brinell hardness measurements have been also done by Frint et al. ${ }^{63)}$ on oxygen free high conductivity copper (purity better than $4 \mathrm{~N}$ ) ECAPed 4 and 8 passes route E (successive $180^{\circ}$ and $90^{\circ}$ rotations) through a laboratory scale $(15 \mathrm{~mm} \times$ $15 \mathrm{~mm})$ and large scale $(50 \mathrm{~mm} \times 50 \mathrm{~mm})$ friction-reduced die applying a back pressure of $75 \mathrm{MPa}$. The results show a linear increase from top to bottom in the zone of homogeneous shear (Fig. 11). The hardness increase from top to bottom is $6 \%$ and $4 \%$ after 4 and 8 passes, respectively, independent of die size. Consequently, the hardness gradient is higher in the small die (4 passes: small $0.60 \mathrm{HBW} / \mathrm{mm}$, large $0.18 \mathrm{HBW} / \mathrm{mm}$; 8 passes: small $0.40 \mathrm{HBW} / \mathrm{mm}$, large $0.12 \mathrm{HBW} / \mathrm{mm}$ ) yielding an increase by a factor 3.3 which corresponds to the ratio of the die widths. Investigations of the microstructure on the large scale billets reveal a gradient in grain size and percentage of HAGBs after 4 passes (top location A: $2.9 \mu \mathrm{m}, 25 \%$; bottom location B: $2.1 \mu \mathrm{m}(1.8 \mu \mathrm{m}$, laboratory scale), $31 \%(32 \%)$ ), while after 8 passes the microstructures are similar (A: $1.1 \mu \mathrm{m}, 47 \%$; B: $1.1 \mu \mathrm{m}$ $(1.2 \mu \mathrm{m}), 48 \%(46 \%))$. However, mappings of HAGBs reveal a quite heterogeneous grain structure after 4 passes getting more homogeneous after 8 passes. The grain refinement is moderate as well as the fraction of HAGBs which may be due to the high purity $\mathrm{Cu}$ and special ECAP route used. The grain structure is the same for laboratory and large scale billets 


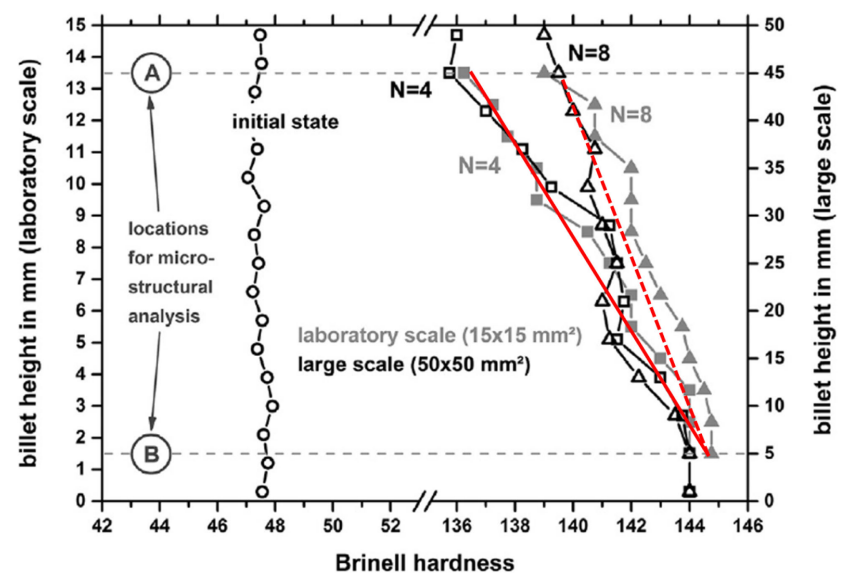

Fig. 11 Distribution of average hardness from a set of longitudinal indents plotted as a function of billet height for OFHC $\mathrm{Cu}$ after 4 and 8 passes of small and large scale ECAP following route $E$ with $75 \mathrm{MPa}$ back pressure. The strength gradient is approximated by straight red lines. The results for the initial state are included for reference, and locations used for microstructural features mentioned are highlighted as A and $\mathrm{B} .{ }^{63)}$

after 8 passes. Hence, it cannot be responsible for the hardness increase. Therefore, its origin may be related to the texture gradient generally observed giving rise to a gradient in Taylor factor. Unfortunately, a quantitative texture analysis from top to bottom of the billet is missing. However, this conclusion is anything but assuring because the strength increase is quite weak (smaller than 10\%) and requires a very small experimental scatter of grain size and texture measurements which usually is not given. Thus, it is difficult to separate their contributions to strength and to determine the dominant one. Grain refinement with increasing number of ECAP passes generally leads to texture weakening and thus to alleviating texture effects on strengthening. ${ }^{78)}$

\section{Material Properties}

It has been shown, that the development of microstructure and texture during ECAP strongly depends on their starting state. This relates to grain size, alignment of grain long axis, degree of pre-deformation, texture strength and preferred orientation alignment. The most extreme case from the academic point of view is starting with single crystals of different orientation. The influence of the initial microstructure and texture vanishes after a certain number of ECAP passes depending on the initial state and material.

Another material characteristic is the dynamic recovery and recrystallization behavior because it affects workhardening and grain refinement as well as texture development. As dynamic recovery and recrystallization are thermally activated processes they strongly depend on the purity of the material and the processing temperature.

\subsection{Starting microstructure and texture}

An extremely inhomogeneous microstructure and texture has been observed across the cross section of $\mathrm{Ni}$ single crystals ECAPed one pass through a friction-reduced lubricated rectangular die $(10 \mathrm{~mm} \times 10 \mathrm{~mm})$ with sharp corners. ${ }^{14,18,19,25,29,82)}$ The heterogeneity is in normal direction from top to bottom as well as in transverse direction symmetrical to the middle. ECAP of a cube oriented single crystal $(\{110\}$ and $\langle 110\rangle$ parallel to ideal shear plane and shear direction) leads to a split $C$ component $\left(C_{1}\right.$ and $C_{2}$, rotated around the $C$ position by about $\Delta \phi= \pm 10^{\circ}$ ) and a relatively weak rotated cube component. Near the top and bottom, however, the textures are quite different. At the top position, the texture is the strongest near the rotated cube position. At the bottom position, the cube appears in its original position but it is considerably spread. The microstructure is characterized by a complex banded structure. In the upper part these deformation bands (DBs) belong to the cube component rotated by different angles around TD and extending somewhat towards the ideal $C$ and $A_{1}{ }^{*}$ components. In the central part the matrix either consists of $C_{1}$ or $C_{2}$. It is crossed by non-crystallographic broad DBs with TD-rotated cube orientation. Moreover, both matrix and coarse bands are crossed by fine crystallographic shear bands (CSBs) along $\{111\}$ slip planes. The texture components given by the CSBs are in a $-\Delta \varphi_{1}$ TD-rotated position from the matrix and DB orientation representing just zones of less shear leading to heterogeneous overall straining or strain partitioning. The characteristic features of the lower part are an almost cube oriented matrix crossed by horizontal DBs with $+\Delta \varphi_{1}$ rotation, i.e. larger shear. The instability of the cube orientation leading to fragmentation of the microstructure is discussed in detail in Ref. 19). In the case of ECAP of an orientation with $A_{1}{ }^{*}$ deviating by $\Delta \varphi_{1}=-10^{\circ}$ from the shear plane a similar heterogeneity is observed across the cross section, however it is less pronounced in the microstructure than in the texture. ${ }^{82)}$ The texture in the upper part is mainly characterized by the $C$ component, the central part by $A_{1}{ }^{*}$ and the lower part by the initial orientation. Deformation banding occurs in all parts with bands differing in TD-rotation around the common $\langle 110\rangle$ direction.

Fukuda et al. ${ }^{83)}$ extruded a small $5 \mathrm{~N}$ aluminium single crystal through a die $\left(4 \mathrm{~mm} \times 4 \mathrm{~mm}, \Phi=90^{\circ}, \psi=30^{\circ}\right)$ with the $\{111\}\langle 110\rangle$ slip system oriented parallel to the ideal shear plane and shear direction, respectively ( $A$ starting component). They observed a relatively homogeneous microstructure in the upper and central part with about a $60^{\circ}$ rotation of the initial component around the $\langle 112\rangle$ TD axis approaching the $B$ orientation. In the lower part DBs exist with initial $A$ orientation and the $60^{\circ}$ rotated one. The instability of this orientation was explained by Beyerlein and Toth $^{58)}$ by some misalignment from the ideal orientation into the divergent side of the rotational field of shear. In the case of a $\varphi_{1}=-20^{\circ}$ TD-rotated $A$ orientation the rotation during ECAP was about $40^{\circ}{ }^{84)}$ Fukuda et al. ${ }^{85)}$ repeated the same experiments on $\mathrm{Cu}$ single crystals for the same initial orientations. In the first sample oriented for ideal single slip they observed a similar large rotation to the $B$ shear component, while in the second deviated orientation they only found a $20^{\circ}$ rotation, instead of $40^{\circ}$ for Al. In this case during ECAP the crystal rotation stopped at the ideal $A$ shear component. Heterogeneous deformation during ECAP through a round die with $\Phi=90^{\circ}$ and $\psi=30^{\circ}$ was also observed for seven differently oriented $\mathrm{Cu}$ single crystals $(3 \mathrm{~N}+)$ in the form of DBs. ${ }^{86,87)}$ It is shown that the degree of heterogeneity depends on the initial orientation. 
Unfortunately, the heterogeneity in microstructure and texture was not investigated in detail across the whole cross section.

The effect of starting texture on the texture development during three ECAP passes following route A (frictionreduced lubricated rectangular die $(10 \mathrm{~mm} \times 10 \mathrm{~mm})$ with sharp corners) is demonstrated on aluminium alloy 5109 $\left.{ }^{20}\right)$ for a cube oriented $\left(\mathrm{Al}\left(0^{\circ}\right)\right.$, preferred $\{110\}$ and $\langle 110\rangle$ parallel to ideal shear plane and shear direction, respectively) and $\langle 110\rangle$ oriented polycrystal (Al $\left(45^{\circ}\right)$, preferred $\{112\}$ and $\langle 111\rangle$ parallel to ideal shear plane and shear direction, respectively). There are differences with regard to intensity of the shear components and their deviation from ideal orientation from top to bottom of the billets depending on initial texture and pass number.

\subsection{Dynamic recrystallization}

During ECAP the grains become extremely deformed leading to deformation banding which originates from the ambiguity associated with the selection of the operative slip systems. ${ }^{88)}$ Another origin is given by inhomogeneous straining of the grains. The deformation bands are separated by geometrically necessary boundaries (GNBs). In addition, boundaries are also formed by statistical trapping of dislocations forming so-called incidental dislocation boundaries (IDBs). In general, the misorientation of both types of boundaries increases with strain ${ }^{89)}$ the rate being larger for GNBs. Besides, the spacing of both types of boundaries decreases with increasing deformation indicating that grain subdivision continues to refine with increasing strain. With increasing misorientation this process leads to the formation of new HAGBs the percentage of which increases with strain. Grain fragmentation depends on grain orientation but is also different in the core and mantle of grains due to the geometric requirement for strain accommodation near grain boundaries. ${ }^{69,70)}$ However, with grain refinement the driving force for coarsening of the structure increases. Provided grain boundary motion is slow, i.e. if the time a grain boundary moves across a grain distance is about the time a new boundary develops by the process described above, then a steady state results. This mechanism of grain refinement is known as continuous dynamic recrystallization (CDRX), ${ }^{90)}$ in contrast to discontinuous dynamic recrystallization (DDRX) where massive grain boundary motion leads to a drastic change of the deformation microstructure. As the grain boundary velocity depends on the grain boundary mobility as well as on the driving force given by the dislocation density stored, the transition from one mechanism to the other is strongly affected by deformation temperature, strain rate and purity of the material. If additionally twinning contributes to strain, as is the case for FCC metals with low stacking fault energy, then grain refinement is accelerated and leads to smaller steady state grain size. This has been shown for high entropy alloys deformed by high pressure torsion, where a NG structure has been achieved. ${ }^{91}$ )

Generally, as demonstrated before, CDRX is preferred in SPD because it leads to highest grain refinement and therefore to highest strength. However, in the following the other extreme case, DDRX, will be demonstrated on high purity aluminium $(5 \mathrm{~N})$ ECAPed at room temperature through a lubricated rectangular die $(10 \mathrm{~mm} \times 10 \mathrm{~mm})$ with sharp corners. ${ }^{15,22)}$ During each ECAP pass, the pure aluminium completely dynamically recrystallizes. The grain size distribution becomes narrower and the mean grain size reduces only by a factor of about 3 to 4 . The grains have an oblate shape with an aspect ratio of about 2 and in the $X Y$ plane are inclined to the $\mathrm{X}$-direction. With increasing number of passes this angle increases, in contrast to a decrease in simple shear deformation (without recrystallization), ${ }^{15,92)}$ while in the YZ-plane it is about zero. The overall fraction of HAGBs for all states is about $70 \%$. There is no systematic change in the microstructural parameters in the $\mathrm{X}$ - and $\mathrm{Z}$ directions of the billets. However, in Y-direction there seems to be a slight increase of grain size in the bottom part (7-10 mm).

The global texture of the billets measured by neutron diffraction is characterized by a relatively strong $\langle 100\rangle$-fibre in $Y$-direction (Fig. 12). During ECAP, the texture changes to a cube component rotated anticlockwise around the transverse direction, i.e. Z-axis. Similar to the microstructure, the local texture measured by EBSD did not show any systematic deviation in X- and Z-direction. However, in Y-direction, a gradual decrease of $\varphi_{1}$ is apparent from the top to the bottom of the billets (inset in Fig. 12). In the bottom part (7-10 mm), $\varphi_{1}$ increases again. At a constant position, $\varphi_{1}$ increases with the number of passes. In the central part of the billet the microstructure (grain size, aspect ratio, grain shape preferred orientation) does not change systematically in Y-direction (along the height), except in the lower third, where the grain size is found slightly larger than in the rest of the billet. In contrast, the texture changes in a characteristic manner with respect to the deviation of the cube component from the ideal position. The deviation decreases from top to bottom down to the lower third and then increases again. This behaviour can be explained in the light of the flow line model developed by Tóth et $a .^{22,69}$ ), where there is only one parameter; the exponent $n$, expressing the shape of the flow line. Fitting this model to a deformed grid of an ECAP aluminum alloy ${ }^{13,31,70)}$ yields flow line exponents $n$ increasing from top to bottom (s. Fig. 3). It follows then from the flow line model that the plastic strain increases, too. The smallest $n$ value $(n=2)$ is expected at the top, the largest $\mathrm{n} \rightarrow \infty$ corresponds to the bottom (by disregarding the friction for a moment). The strain increase, nevertheless, is quite limited because the equivalent von Mises strain is 0.91 for $n=2$ and 1.15 for $n \rightarrow \infty$. (This feature is also predicted by finite element method results of $\mathrm{ECAP}^{38}$ ). As the total strain experienced along a flow line is large, this $25 \%$ difference should just slightly affect the relative intensities of the textures corresponding to different flow lines. There is, however, another effect, related to the shapes of the flow lines, which leads to different rotations of the texture components as a function of the $\mathrm{n}$ value. As is shown in Ref. 69), the rotation decreases as $\mathrm{n}$ increases (this rotation is in the anticlockwise direction around TD). It is then expected from the flow line model that the texture is less rotated towards the bottom. Assuming the recrystallization texture to be symmetrically related to the deformation texture the same rotation effect should be observed, in agreement with experiment (Fig. 12). Nevertheless, the lower part of the 

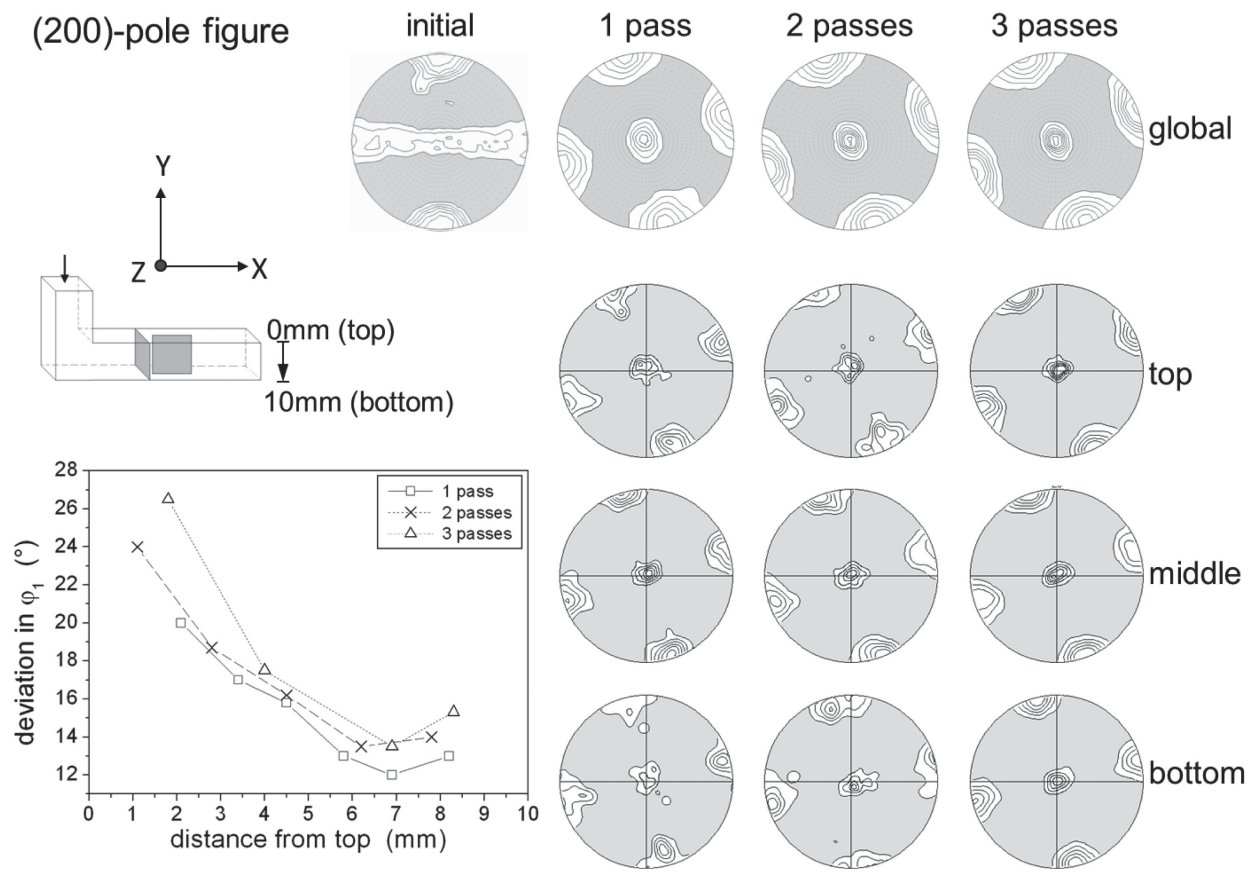

Fig. 12 (200) pole figures of the initial and deformed state of high purity aluminium (5N). Global textures measured by neutron diffraction (contour lines: 1-6 and $8 \mathrm{mrd}$ ); local textures measured by EBSD in the top, middle and bottom part of the sample, respectively (contour lines: $2,4,6,8,10,12$ and $14 \mathrm{mrd}$ ). Inset shows the deviation in $\varphi_{1}$ of the cube component from the ideal position. ${ }^{22)}$

billet (of about $30 \%$ of the total width) shows a reverse behavior. According to experiment and simulation, ${ }^{13)}$ because of friction, this zone experiences a lower shear strain decreasing drastically to the bottom of the billet.

During ECAP the grains are sheared and thus become elongated. The inclination of the grain long axis with the extrusion direction decreases with increasing number of passes. However, if DDRX takes place then at a critical strain the "finite strain clock" is periodically reset yielding a "steady state" grain shape foliation. ${ }^{93,94)}$

The recrystallization texture, i.e. the oblique cube component, is totally different from the deformation textures usually found for ECAP deformed FCC metals. The deformation texture consists of typical shear components rotated from their ideal positions around the transverse direction. ${ }^{16,18,20,69,95)}$ The intensity of the components and the deviation from their ideal positions depend on the stacking fault energy of the material ${ }^{92,96)}$ and the starting texture. ${ }^{20)}$ The recrystallization component does not belong to the set of deformation components. A cube component has also been reported recently for $4 \mathrm{~N}$ aluminium deformed by ECAP following Route $B_{C} \cdot{ }^{97}$ )

Pure aluminium prefers to develop a cube texture during recrystallization after rolling. In the following it is assumed that DDRX takes place by growth of nuclei that are oriented in the cube position. This is well accepted in rolling. ${ }^{88)}$ What is different in ECAP is of course, the shear strain. From a simple mechanical strain analysis, simple shear can also be considered as a composition of tension and compression, which actually is rolling. This also comes out from the flow line model which nicely shows the tension and compression components. ${ }^{69)}$ They are actually the main components of the strain. The 'small' problem is that there is also a rigid body rotation in the analysis. This rigid body rotation completely changes the texture evolution with respect to rolling. However, it does not change the event that the cube component is initiated as in rolling, that is the nuclei are in the non-rotated cube position. Once the nucleus exists, it is subjected to the orientation flow as any other grain. Luckily, for the cube component, there is no plastic spin, so it just rotates with the imposed rigid body spin under simple shear. ${ }^{100)}$ The initially cube oriented nucleus grows and rotates by the rigid body spin. Its initial cube orientation, however, has a very small intensity as the nuclei have a very small volume fraction. Their volume fraction, however, increases with time as they grow by grain boundary migration, consuming the neighbors. Because of this, their volume fraction continuously increases and they appear with high intensity in the texture. During this growth these grains also rotate by the rigid body spin. However, such an individual grain has to disappear after a certain strain. This is because DDRX does not stop, it continues, new strain-free nuclei will consume the rotated cube position grains. Consequently, the rotation of these grains stops as they must disappear. These orientations will then be replaced by the new growing nuclei. This is why there is a constant angle of rotation of the cube component.

One can calculate then the shear deformation during which a growing grain can exist. It is equal to the rotation angle from the ideal cube position in radian multiplied with 2 . In the top positions the rotation is about $25^{\circ}$, which yields a shear strain of 0.87 . This strain, however, seems to decrease towards the bottom position because the rotation angles decreases. The explanation can be that the strain mode is not exactly simple shear everywhere. At positions where the strain mode approaches better the tension-compression situation without significant rigid body rotation, this rotation angle must be smaller. It seems that in the bottom part, the 
rigid body rotation is much smaller. Actually, it is quite possible because friction works in the opposite direction with respect to the simple shear process, thus, reducing the rigid body rotation.

No hardness measurements have been done on the samples after DDRX. However, according to the texture-induced change of Taylor factor $M$ from top to bottom of the billets $\left(M^{\langle 100\rangle}=2.45, \quad M^{\langle 110\rangle}=M^{\langle 111\rangle}=3.67^{101)}\right) \quad$ the hardness should change in the same way as the deviation in $\varphi_{1}$ of the cube component from the ideal position (Fig. 12), i.e. go through a minimum from top to bottom, opposite to the texture gradient developing during CDRX determined by deformation.

\section{Conclusions}

Within the vast amount of research done on ECAP during the last three decades, only a quite small fraction of publications systematically but in general not simultaneously deal with the heterogeneities in microstructure, texture and mechanical properties developing in the billets. Nevertheless, based on the results presented in this overview the following conclusions can be drawn:

In the ideal case of ECAP (sharp die corners, no friction, rigid plastic material behavior) deformation is by simple shear in a narrow zone along the die intersection plane. Deviations from this behavior arise when these conditions are not fulfilled. In this case deformation takes place in a much broader zone the shape of which depends on die design, processing conditions and material properties. By varying these factors it turned out that the shearing of the sample is most homogeneous when using a friction-reduced die and applying a back pressure. Nevertheless, there exists an increase in strength from top to bottom of the billet, except in the lowest section where the material is softer. This section can be almost eliminated by increasing the back pressure. The strength increase from top to bottom is smaller than $10 \%$ and decreases with the number of passes. The strength increase is the same for laboratory and industrial-scale samples. Consequently, the strength gradient is smaller in bigger samples. Thus, upscaling improves the homogeneity in a comparable volume and therefore favors technical applications. The strength gradient via Hall-Petch relation and Taylor factor may be related to the gradient in microstructure and/or texture generally observed. However, because of the experimental scatter in grain size and texture measurements, it is difficult to unambiguously separate their contribution to the relatively weak inherent strength heterogeneity in ECAP. In general, the ECAP microstructure also consists of a high dislocation density mainly determining the strength of the material. However, so far it has not been reported how the density and arrangement of dislocations is affected by the heterogeneous flow and strain path changes during ECAP.

\section{Acknowledgement}

The author is grateful to the many coworkers mentioned in his publications that greatly helped to enlighten the complex problem of deformation heterogeneity in ECAP. Thanks are also due to Dr. M. Hockauf (formerly TU Chemnitz) for microhardness measurements presented in Fig. 10.

\section{REFERENCES}

1) http://en.wikipedia.org/wiki/severe_plastic_deformation.

2) R.Z. Valiev, Y. Estrin, Z. Horita, T.G. Langdon, M.J. Zehetbauer and Y.T. Zhu: JOM 58(4) (2006) 33-39.

3) V.M. Segal, I.J. Beyerlein, C.N. Tomé, V.N. Chuvil'deev and V.I. Kopylov: Fundamentals and Engineering of Severe Plastic Deformation, (Materials Science and Technologies Series, Nova Science Publishers, Inc., New York, 2010).

4) V.M. Segal: Method of material preparation for subsequent working, (USSR-Patent Nr. 575892 english translation, 1977).

5) R.Z. Valiev, R.K. Islamgaliev and I.V. Alexandrov: Prog. Mater. Sci. 45 (2000) 103-189.

6) R.Z. Valiev and T.G. Langdon: Prog. Mater. Sci. 51 (2006) 881-981.

7) V.M. Segal, V.I. Reznikov, A.E. Dobryshevski and V.I. Kopylov: Russ. Metall. 1 (1981) 99-105.

8) V.M. Segal: Severe Plastic Deformation Technology, ed. by A. Rosochowski, (Whittles Publishing, Dunbeath, 2017).

9) T.G. Langdon, M. Furukawa, M. Nemoto and Z. Horita: JOM 52(4) (2000) 30-33.

10) R.Z. Valiev: Adv. Eng. Mater. 5 (2003) 296-300.

11) C. Xu, M. Furukawa, Z. Horita and T.G. Langdon: Adv. Eng. Mater. 5 (2003) 359-364.

12) M. Furukawa, Z. Horita, M. Nemoto and T.G. Langdon: J. Mater. Sci. 36 (2001) 2835-2843.

13) J.R. Bowen, A. Gholinia, S.M. Roberts and P.B. Pragnell: Mater. Sci. Eng. A 287 (2000) 87-99.

14) D. Goran, S. Suwas, J.-J. Fundenberger, E. Bouzy, L.S. Tóth, W. Skrotzki and T. Grosdidier: Solid State Phenomena 105 (2005) 333338.

15) W. Skrotzki, N. Scheerbaum, C.-G. Oertel, H.-G. Brokmeier, S. Suwas and L.S. Tóth: Solid State Phenomena 105 (2005) 351-356.

16) W. Skrotzki, N. Scheerbaum, C.-G. Oertel, H.-G. Brokmeier, S. Suwas and L.S. Tóth: Solid State Phenomena 105 (2005) 327-332.

17) W. Skrotzki, B. Klöden, N. Scheerbaum, R. Tamm, C.-G. Oertel, U. Garbe, E. Rybacki and H.-G. Brokmeier: Advanced X-ray Techniques in Research and Industry, ed. by A.K. Singh, (Capital Publishing Company, New Delhi, and IOS Press, Amsterdam, 2005) pp. 33-49.

18) W. Skrotzki, N. Scheerbaum, C.-G. Oertel, H.-G. Brokmeier, S. Suwas and L.S. Tóth: Mater. Sci. Forum 495-497 (2005) 821-826.

19) D. Goran, S. Suwas, J.-J. Fundenberger, E. Bouzy, L.S. Tóth, W. Skrotzki and T. Grosdidier: Mater. Sci. Forum 495-497 (2005) 833838 .

20) W. Skrotzki, N. Scheerbaum, C.-G. Oertel, H.-G. Brokmeier, S Suwas and L.S. Tóth: Mater. Sci. Forum 503-504 (2006) 99-106.

21) W. Skrotzki, B. Klöden, C.-G. Oertel, N. Scheerbaum, H.-G. Brokmeier, S. Suwas and L.S. Tóth: Ultrafine Grained Materials IV, ed. by Y.T. Zhu, T.G. Langdon, Z. Horita, M.J. Zehetbauer, S.L. Semiatin and T.C. Lowe, (TMS, The Minerals, Metals \& Materials Society, 2006) pp. 283-288.

22) W. Skrotzki, N. Scheerbaum, C.-G. Oertel, H.-G. Brokmeier, S. Suwas and L.S. Tóth: Acta Mater. 55 (2007) 2211-2218.

23) W. Skrotzki, N. Scheerbaum, C.-G. Oertel, R. Arruffat-Massion, S. Suwas and L.S. Tóth: Acta Mater. 55 (2007) 2013-2024.

24) W. Skrotzki, B. Klöden, I. Hünsche, R. Chulist, S. Suwas and L.S. Tóth: Mater. Sci. Forum 558-559 (2007) 575-580.

25) T. Grosdidier, J.-J. Fundenberger, D. Goran, E. Bouzy, S. Suwas, W. Skrotzki and L.S. Tóth: Scr. Mater. 59 (2008) 1087-1090.

26) W. Skrotzki, L.S. Tóth, B. Klöden, H.-G. Brokmeier and R. ArruffatMassion: Acta Mater. 56 (2008) 3439-3449.

27) W. Skrotzki, B. Klöden, A. Lankau, R. Chulist, V. Kopylov and H.-G. Brokmeier: Arch. Metall. Mater. 53 (2008) 29-32.

28) W. Skrotzki, C. Tränkner, R. Chulist, B. Beausir, S. Suwas and L.S. Tóth: Solid State Phenomena 160 (2010) 47-54.

29) D. Goran, J.-J. Fundenberger, W. Skrotzki, S. Suwas, L.S. Tóth and T. Grosdidier: Philos. Mag. 91 (2011) 281-299.

30) A. Panigrahi, N. Scheerbaum, P. Chekhonin, J. Scharnweber, B. 
Beausir, M. Hockauf, S. Sankaran and W. Skrotzki: IOP Conf. Ser.: Mater. Sci. Eng. 63 (2014) 012153.

31) J.R. Bowen: PhD Thesis, The University of Manchester, (2000).

32) A. Shan, I.-G. Moon, H.-S. Ko and J.-W. Park: Scr. Mater. 41 (1999) 353-357.

33) J.C. Werenskiold and H.J. Roven: Nanomaterials by Severe Plastic Deformation, ed. by M.J. Zehetbauer and R.Z. Valiev, (Wiley-VCH, Weinheim, 2004) pp. 591-603.

34) H.J. Roven, S. Dumoulin and J.C. Werenskiold: Ultrafine Grained Materials III, ed. by Y.T. Zhu, T.G. Langdon, R.Z. Valiev, S.L. Semiatin, D.H. Shin and T.C. Lowe, (TMS, Charlotte, 2004) pp. $117-$ 124.

35) P.B. Prangnell, C. Harris and S.M. Roberts: Scr. Mater. 37 (1997) 983-989.

36) H.S. Kim, H.H. Seo and S.I. Hong: Mater. Sci. Eng. A 291 (2000) 8690.

37) S.L. Semiatin, D.L. Delo and E.B. Shell: Acta Mater. 48 (2000) 18411851

38) J.-Y. Suh, H.-S. Kim, J.-W. Park and J.-Y. Chang: Scr. Mater. 44 (2001) 677-681.

39) J.-W. Park and J.-Y. Suh: Metall. Mater. Trans. A 32 (2001) 30073014.

40) H.S. Kim, H.H. Seo and S.I. Hong: J. Mater. Res. 16 (2001) 856-864.

41) H.S. Kim: J. Mater. Res. 17 (2002) 172-179.

42) S. Li, I.J. Beyerlein, C.T. Necker, D.J. Alexander and M. Bourke: Acta Mater. 52 (2004) 4859-4875.

43) I.N. Budilov, I.V. Alexandrov, Y.V. Lukaschuk, I.J. Beyerlein and V.S. Zhernakov: Ultrafine Grained Materials, ed. by Y.T. Zhu, T.G Langdon, R.Z. Valiev, S.L. Semiatin, D.H. Shin and T.C. Lowe, (TMS, Charlotte, 2004) pp. 193-198.

44) W.J. Kim, J.C. Namgung and J.K. Kim: Scr. Mater. 53 (2005) 293 298.

45) I.J. Beyerlein, S. Li, T. Necker, D.J. Alexander and C.N. Tomé: Philos. Mag. 85 (2005) 1359-1394.

46) V.M. Segal: Mater. Sci. Eng. A 345 (2003) 36-46.

47) T. Suo, Y. Li, Y. Guo and Y. Liu: Mater. Sci. Eng. A 432 (2006) 269_ 274.

48) V.S. Zhernakov, I.N. Budilov, I.V. Alexandrov and I.J. Beyerlein: J. Mater. Res. 98 (2007) 178-183.

49) D.P. DeLo and S.L. Semiatin: Metall. Mater. Trans. A 30 (1999) 1391-1402.

50) H.J. Cui, R.E. Goforth and K.T. Hartwig: JOM-e 50(8) (1998) 1-5.

51) S. Li, S.R. Kalidindi and I.J. Beyerlein: Mater. Sci. Eng. A 410-411 (2005) 207-212.

52) S.W. Chung, H. Somekawa, T. Kinoshita, W.J. Kim and K. Higashi Scr. Mater. 50 (2004) 1079-1083.

53) W.J. Kim and J.C. Namkung: Mater. Sci. Eng. A 412 (2005) 287-297.

54) F. Kang, J.T. Wang, Y.L. Su and K.N. Xin: J. Mater. Sci. 42 (2007) 1491-1500

55) H.S. Kim: Bulk Nanostructured Materials, ed. by M.J. Zehetbauer and Y.T. Zhu, (Wiley-VCH, Weinheim, 2009) pp. 137-163.

56) V.M. Segal: Mater. Sci. Eng. A 345 (2003) 36-46.

57) G.M. Stoica and P.K. Liaw: Materials Lifetime Science \& Engineering, (TMS, 2003) pp. 119-133.

58) I.J. Beyerlein and L.S. Tóth: Prog. Mater. Sci. 54 (2009) 427-510.

59) V.M. Segal: Mater. Sci. Eng. A 197 (1995) 157-164.

60) V.M. Segal: Mater. Sci. Eng. A 271 (1999) 322-333.

61) Z. Horita, T. Fujinami and T.G. Langdon: Mater. Sci. Eng. A 318 (2001) 34-41.

62) Z. Horita: Bulk Nanostructured Materials ed. by M.J. Zehetbauer and Y.T. Zhu, (Wiley-VCH, Weinheim, 2009) pp. 203-215.

63) S. Frint, M. Hockauf, P. Frint and M.F.-X. Wagner: Mater. Des. 97 (2016) 502-511.

64) Y. Iwahashi, J. Wang, M. Nemoto and T.G. Langdon: Scr. Mater. 35 (1996) 143-146.

65) J.-P. Mathieu, S. Suwas, A. Eberhardt, L.S. Tóth and P. Moll: Processing Technol. 173 (2006) 29-33.
66) C. Tränkner: Diploma Thesis, Technische Universität Dresden, (2010).

67) M. Furukawa, Y. Iwahashi, Z. Horita, M. Nemoto and T.G. Langdon: Mater. Sci. Eng. A 257 (1998) 328-332.

68) H. Bunge: Texture Analysis in Materials Science, Mathematical Methods, (Culliver Verlag, Göttingen, 1993).

69) L.S. Tóth: Adv. Eng. Mater. 5 (2003) 308-316.

70) L.S. Tóth, R. Massion, L. Germain and S.C. Baik: Acta Mater. 52 (2004) 1885-1898.

71) R.Y. Lapovok: J. Mater. Sci. 40 (2005) 341-346.

72) V.V. Stolyarov, R. Lapovok, I.G. Brodova and P.F. Thomson: Mater. Sci. Eng. A 357 (2003) 159-167.

73) A. Hasani, R. Lapovok, L.S. Tóth and A. Molinari: Scr. Mater. 58 (2008) 771-774.

74) P.W.J. Mckenzie, R. Lapovok and Y. Estrin: Acta Mater. 55 (2007) 2985-2993.

75) P.W.J. Mckenzie and R. Lapovok: Acta Mater. 58 (2010) 3198-3211.

76) A. Mogucheva, E. Babich, B. Ovsyannikov and R. Kaibyshev: Mater. Sci. Eng. A 560 (2013) 178-192.

77) P.W.J. Mckenzie and R. Lapovok: Acta Mater. 58 (2010) 3212-3222.

78) L.S. Tóth, Y. Estrin, R. Lapovok and C. Gu: Acta Mater. 58 (2010) 1782-1794.

79) P. Frint, M. Hockauf, D. Dietrich, T. Halle, M.F.-X. Wagner and T. Lampke: Materialwiss. Werkst. 42 (2011) 680-685.

80) P. Frint, M. Hockauf, T. Halle, M.F.-X. Wagner and T. Lampke: Materialwiss. Werkst. 43 (2012) 668-672.

81) P. Frint, M. Hockauf, T. Halle, G. Strehl, T. Lampke and M.F.-X. Wagner: Mater. Sci. Forum 667-669 (2010) 1153-1158.

82) D. Goran: PhD Thesis, Université Paul Verlaine de Metz, (2007).

83) Y. Fukuda, K. Oh-ishi, M. Furukawa, Z. Horita and T.G. Langdon: Acta Mater. 52 (2004) 1387-1395.

84) Y. Fukuda, K. Oh-ishi, M. Furukawa, Z. Horita and T.G. Langdon: Mater. Sci. Eng. A 420 (2006) 79-86.

85) Y. Fukuda, K. Oh-ishi, M. Furukawa, Z. Horita and T.G. Langdon: J. Mater. Sci. 42 (2007) 1501-1511.

86) H. Miyamoto, U. Erb, T. Koyama, T. Mimaki, A. Vinogradov and S. Hashimoto: Philos. Mag. Lett. 84 (2004) 235-243.

87) H. Miyamoto, J. Fushimi, T. Mimaki, A. Vinogradov and S. Hashimoto: Mater. Sci. Eng. A 405 (2005) 221-232.

88) F.J. Humphreys and M. Hatherly: Recrystallization and Related Annealing Phenomena, (Elsevier, Oxford, 2004).

89) N. Hansen: Metall. Mater. Trans. A 32 (2001) 2917-2935.

90) F. Montheillet and J. Le Coze: Phys. Status Solidi A 189 (2002) 5158 .

91) W. Skrotzki, A. Pukenas, B. Joni, E. Odor, T. Ungar, A. Hohenwarter, R. Pippan and E.P. George: IOP Conf. Ser.: Mater. Sci. Eng. 194 (2017) 012028.

92) S. Suwas, L.S. Tóth, J.-J. Fundenberger, A. Eberhardt and W. Skrotzki: Scr. Mater. 49 (2003) 1203-1208.

93) G.S. Lister and A.W. Snoke: J. Struct. Geol. 6 (1984) 617-638.

94) E. Rybacki, M.S. Paterson, R. Wirth and G. Dresen: J. Geophys. Res. 108 (2003) ETG 8-1-ETG 8-24.

95) N. Scheerbaum: Diploma Thesis, Technische Universität Dresden, (2004).

96) S. Suwas, L.S. Tóth, J.-J. Fundenberger, T. Grosdidier and W. Skrotzki: Solid State Phenom. 105 (2005) 345-350.

97) A.A. Salem, Z. Horita, T.G. Langdon, T.R. McNelley and S.L. Semiatin: Ultrafine Grained Materials III, ed. by Y.T. Zhu, T.G. Langdon, R.V. Valiev, S.L. Semiatin, D.H. Shin and T.C. Lowe, (TMS, Warrendale, 2004) pp. 81-88.

98) K. Furuno, H. Akamatsu, K. Oh-ishi, M. Furukawa, Z. Horita and T.G. Langdon: Acta Mater. 52 (2004) 2497-2507.

99) M. Nakashima, Z. Horita, M. Nemoto and T.G. Langdon: Mater. Sci. Eng. A 281 (2000) 82-87.

100) L.S. Tóth and J.J. Jonas: Textures Microstruct. 10 (1989) 195-209.

101) W.F. Hosford: Mechanical Behavior of Materials, (Cambridge University Press, Cambridge, 2005). 